\title{
SNAI2/S/ug gene is silenced in prostate cancer and regulates neuroendocrine differentiation, metastasis-suppressor and pluripotency gene expression
}

\author{
Silvia Esposito ${ }^{1,2, *}$, Marco V. Russo ${ }^{1,2, *}$, Irma Airoldi ${ }^{4}$, Maria Grazia Tupone ${ }^{1,2}$, \\ Carlo Sorrentino ${ }^{1,2,3}$, Giulia Barbarito ${ }^{4}$, Serena Di Meo ${ }^{1,2}$, Emma Di Carlo ${ }^{1,2}$ \\ ${ }^{1}$ Department of Medicine and Sciences of Aging, Section of Anatomic Pathology and Molecular Medicine, "G. d'Annunzio" \\ University, Chieti, Italy \\ ${ }^{2}$ Ce.S.I. Aging Research Center, "G. d'Annunzio" University Foundation, Chieti, Italy \\ ${ }^{3}$ Specialisation School in Clinical Biochemistry, "G. d'Annunzio" University, Chieti, Italy \\ ${ }^{4}$ Laboratory of Oncology, Istituto Giannina Gaslini, Genova, Italy \\ *These authors have contributed equally to this work \\ Correspondence to: \\ Emma Di Carlo, e-mail: edicarlo@unich.it \\ Keywords: Prostate Cancer, Neuroendocrine Differentiation, Laser Capture Microdissection, SNAI2/Slug \\ Received: August 25, $2014 \quad$ Accepted: November 11, $2014 \quad$ Published: February 18, 2015
}

\section{ABSTRACT}

Prostate Cancer (PCa)-related deaths are mostly due to metastasization of poorly differentiated adenocarcinomas often endowed with neuroendocrine differentiation (NED) areas.

The SNAI2/Slug gene is a major regulator of cell migration and tumor metastasization. We here assessed its biological significance in NED, and metastatic potential of PCa.

SNAI2 expression was down-regulated in most PCa epithelia, in association with gene promoter methylation, except for cell clusters forming: a. the expansion/invasion front of high-grade PCa, b. NED areas, or c. lymph node metastasis.

Knockdown of SNAI2 in PC3 cells down-regulated the expression of neuraltissue-associated adhesion molecules, Neural-Cadherin, Neural-Cadherin-2, NeuronalCell-Adhesion-Molecule, and of the NED marker Neuron-Specific Enolase, whereas it abolished Chromogranin-A expression. The metastasis-suppressor genes, Nm23-H1 and KISS1, were up-regulated, while the pluripotency genes SOX2, NOTCH1, CD44v6, WWTR1/TAZ and YAP1 were dramatically down-regulated. Over-expression of SNAI2 in DU145 cells substantiated its ability to regulate metastasis-suppressor, NED and pluripotency genes. In PCa and lymph node metastasis, expression of SOX2 and NOTCH1 was highly related to that of SNAI2.

In conclusion, I. SNAI2 silencing in PCa may turn-off the expression of NED markers and pluripotency genes, while turning-on that of specific metastasissuppressors, II. SNAI2 expression in selected PCa cells, by regulating their self-renewal, NED and metastatic potential, endows them with highly malignant properties. SNAI2 may thus constitute a key target for modern approaches to PCa progression.

\section{INTRODUCTION}

The metastatic spread is responsible for most PCarelated deaths. A key event during its early phases is the reactivation of a latent embryonic program, known as epithelial-to-mesenchymal transition (EMT), whereby transformed epithelial cells acquire mesenchymal traits and migratory ability. SNAI2, also known as Slug or SNAIL2 gene, plays a major role in this complex cell and genetic program $[1,2]$. 
SNAI2 encodes a zinc-finger protein of the Snail family of transcription factors. During embryonic development, SNAI2 is expressed in the dorsal neural tube [3] and drives EMT which leads to mesodermal and neural crest cell migration [4]. In post-natal life, the SNAI2 gene is widely expressed in adult human tissues, including the prostate [5, 6], while its amplification [1] or interaction with specific oncogenes $[5,7]$ have been demonstrated in a wide spectrum of human cancers.

Studies performed in cell and human tumor xenograft models of $\mathrm{PCa}$ have revealed that SNAI2 promotes cell migration and invasion and is a critical mediator of Cyclin D1b-induced oncogenic activity $[8,9]$. It has been recently found that Slug is critically involved in determining the stem cell state of mammary cancer [10]. This property, in turn, may condition the differentiation of cancer and correlate with its aggressiveness [11, 12].

Since the histological hallmark of aggressive $\mathrm{PCa}$ is a poorly differentiated glandular architecture of high Gleason grade and presence of nests of neuroendocrine cells, namely neuroendocrine differentiaton (NED) areas [13, 14], it may be supposed that SNAI2's role in prostate carcinogenesis involves the regulation of stem cell- or NED-associated genes.

We here investigated the SNAI2 expression profile in microdissected $\mathrm{PCa}$ foci with different grades of differentiation, established the mechanisms underlying its regulation, and revealed new aspects of its implications in the differentiation and malignant evolution of PCa.

\section{RESULTS}

\section{SNAI2 gene expression level was down-regulated in neoplastic epithelia of both well and poorly differentiated PCa}

To clarify the biological functions of SNAI2 in human prostate carcinogenesis, we first assessed its expression levels in cell populations microdissected from both epithelial and stromal compartments of $\mathrm{PCa}$ foci with low (well differentiated) or high (poorly differentiated) Gleason grade ( $\leq 3$ versus $>3$ ), and from their histologically normal counterparts harvested far from the cancer (Figure 1A and 1B). The mean level of SNAI2 mRNA of malignant stroma was not significantly different from that of the normal counterpart, whereas it was considerably $(p<0.05)$ down-regulated in the neoplastic epithelial cell populations from both low- ( 14 times) and high- ( $\sim 16$ times) grade PCa (with no appreciable difference between them) (Figure 1A), in comparison with the normal epithelium.

SNAI2 expression levels in the normal prostatic epithelium and stroma were comparable to those found in normal epithelium and stroma from control patient samples. No significant association was disclosed by the Mann-Whitney U or the $\chi^{2}$ test between SNAI2 expression levels and any of the clinical and pathological parameters (Supplemental Tables S1-S3).
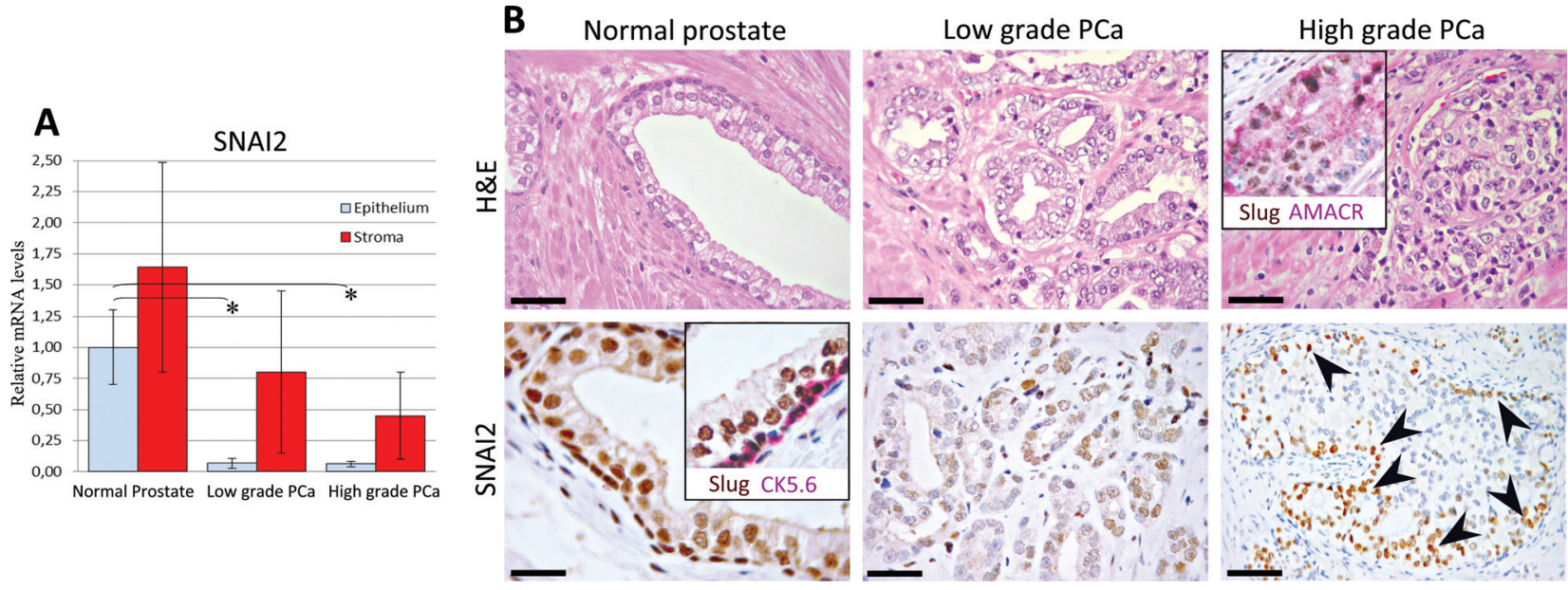

Figure 1: Expression of SNAI2 in normal and neoplastic prostate tissue. (A) $S N A I 2$ mRNA expression in normal and cancerous prostate tissues from PCa patients. Histogram representing the relative expression $\pm \mathrm{SD}$ of SNAI2 mRNA in microdissected histologically normal epithelium and stroma, and their neoplastic counterparts with low or high Gleason grades, from prostatectomized patients (groups of 15), normalized with the housekeeping gene HPRT. One-way ANOVA for comparisons between epithelial compartments of normal prostate, low- and high-grade PCa: $p<0.0001$. ${ }^{*} p<0.01$ Tukey HSD Test compared with normal prostate epithelium. (B) SNAI2 protein expression in normal and cancerous prostate tissues from PCa patients. Prostate tissue from PCa patients displayed a bright SNAI2 nuclear expression in both luminal and basal epithelial cell layer as confirmed by the double SNAI2(brown)/CK5.6(fuchsia) staining (inset in the bottom left panel). SNAI2 expression was frequently lost in malignant epithelium of PCa with either low or high Gleason grades. A strong SNAI2 expression was confined to neoplastic cells bordering high-grade PCa foci, as revealed by double SNAI2(brown)/ AMACR(fuchsia) staining (inset in the upper right panel) and indicated by arrowheads in the single immunostained section (bottom right panel). Magnification: X630, bottom left panel; X200, bottom right panel; X400, the remaining panels. Scale bars: bottom left panel, $20 \mu \mathrm{m}$; bottom right panel, $50 \mu \mathrm{m}$, the remaining panels, $30 \mu \mathrm{m}$. 
To determine whether the lack of SNAI2 expression in the epithelial compartment of PCa was due to absence of the basal cell layer [15], we analyzed $S N A I 2$ expression in distinctly microdissected basal and luminal epithelial components. Since SNAI2 expression levels were not significally different within basal cells, luminal secretory cells and the overall glandular epithelia (Figure 2A), it was evident that SNAI2 down-regulation in PCa was unrelated to this basal cell loss. Similar data were obtained from normal samples of control patients.

\section{Malignant epithelia from PCa mostly displayed SNAI2 gene promoter methylation}

Since DNA methylation marks the entire spectrum of prostate carcinogenesis [16], we next tested its involvement in the loss of SNAI2 gene expression in PCa. Because DNA methylation surrounding the transcription start site (TSS) is closely associated with transcription activity, we performed sodium bisulfite genomic sequencing of the proximal promoter relative
A

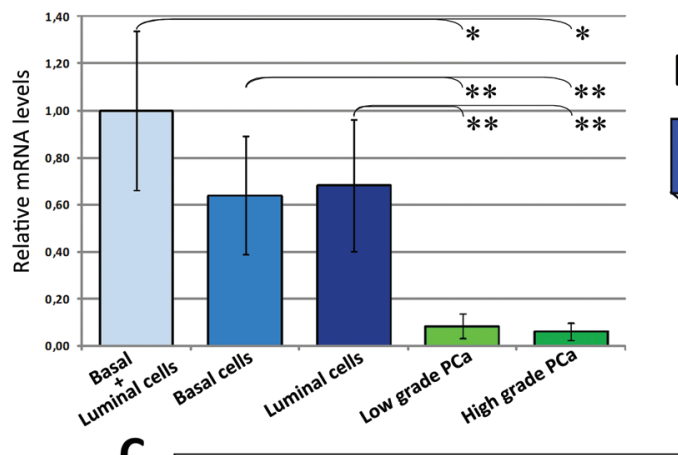

B

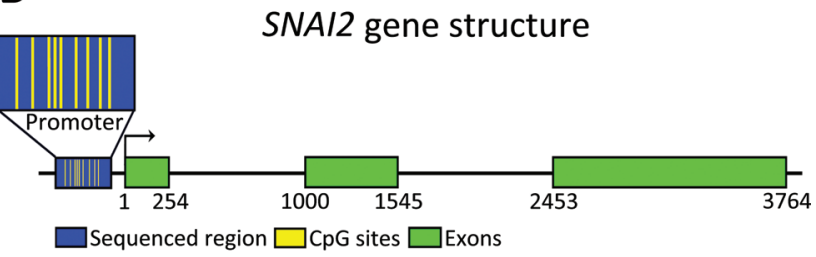

I Unmethylated control DNA

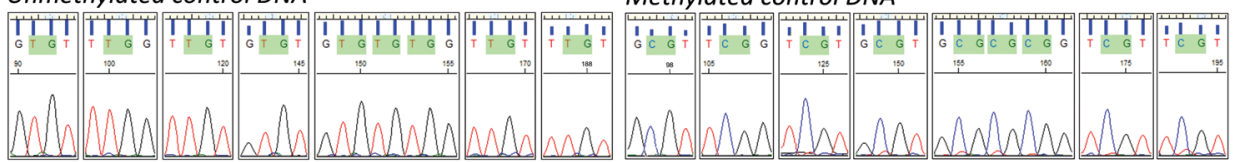

II Normal prostate epithelium Neoplastic prostate epithelium

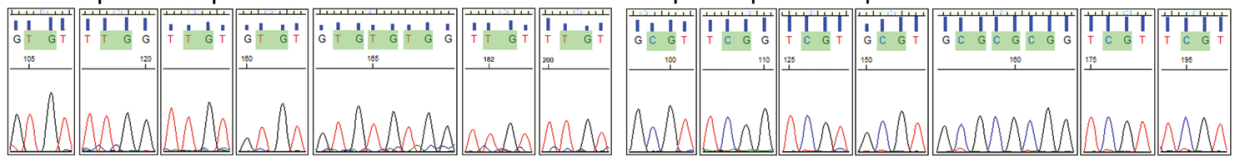

III Edge area of high grade prostate PCa focus Inner area of high grade prostate PCa focus

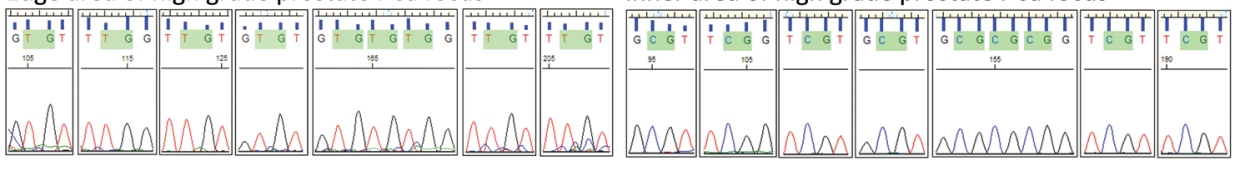

Figure 2: Expression of $S N A I 2$ in normal prostate epithelium and bisulfite genomic sequencing of the proximal promoter region of the SNAI2 gene. (A) SNAI2 mRNA expression in the basal and luminal epithelial cells of normal prostate glands. Histogram representing the relative expression \pm SD of SNAI2 mRNA in microdissected histologically normal basal and luminal secretory epithelium (15 randomly chosen normal samples from PCa patients) and neoplastic epithelium from low and high-grade PCa. One-way ANOVA for comparisons between normal basal and luminal secretory epithelium and neoplastic epithelium from low and highgrade PCa: $p<0.0001 .{ }^{*} p<0.01$ Tukey HSD Test compared with low or high-grade PCa. ${ }^{*} p<0.05$ Tukey HSD Test compared with low or high-grade PCa. (B) DNA methylation status of $\boldsymbol{S N A I 2}$ gene promoter in PCa. The $S N A 12$ gene promoter (blue box) contains 9 sparsely spaced $\mathrm{CpG}$ islands (small yellow bars) in its central portion. (C) Genomic sequencing of the proximal promoter region located 130 bases upstream from the TSS of the $S N A I 2$ gene in microdissected normal and cancerous prostate epithelium, or microdissected cells from the inner and edge areas of high-grade PCa foci. I. The electropherogram shows the methylation status of each $\mathrm{CpG}$ island in control DNA where TG represents the unmethylated site (top left), and CG represents the methylated site (top right). II. CpGs were unmethylated in normal prostate epithelium (middle left) and methylated in neoplastic prostate epithelium (middle right). III. CpGs were unmethylated in cell clusters from the edge area (bottom left), and methylated in cell clusters from the inner area of the high-grade PCa focus (bottom right). 
to a section of $309 \mathrm{bp}$ located 130 bases upstream from the TSS. This promoter region contains 9 sparsely spaced CpGs in its central portion (Figure 2B). They were unmethylated in normal prostate epithelial cells (from normal samples of both $\mathrm{PCa}$ and of control patients), and methylated in the majority of neoplastic cell foci with low- (74\%) and high- $(80 \%)$ grade feature (Figure 2C). These data strongly suggest that the SNAI2 down-regulation observed in most PCa epithelia is linked to hypermethylation of the SNAI2 gene promoter.

\section{SNAI2 expression characterized cancer cell clusters at the invasion/expansion front and NED areas of high-grade PCa, and lymph node metastasis}

SNAI2 expression was immunohistochemically assessed to validate molecular data at the protein level, and also visualize any fluctuation (suggested by the lack of methylation in some of the microdissected cancer cell populations) of its expression within the heterogeneous prostate tissue.

In the stromal compartment of both normal and cancerous prostate tissue, SNAI2 expression was detectable in small mononuclear-like leukocytes, and cells endowed with fibroblast morphology.

The normal glandular epithelium displayed a bright nuclear expression of SNAI2 in both the luminal secretory cells Cytokeratin (CK)18+ and the basal cell CK5.6+ layer (Figure 1B), whereas the neoplastic epithelium (alphamethylacyl-CoA racemase, AMACR+), from both lowand high-grade PCa foci, was mainly devoid of SNAI2 expression (Figure 1B).

SNAI2 protein expression was truly heterogeneous insofar as it differed greatly from one focus to another and even within the same focus. In particular, a distinct to strong expression was confined to few cancer foci endowed with low (9/35) or high Gleason grade (13/67) (Figure 3A), and to cancer cell clusters bordering the expansion/invasion front of (58/67) high-grade poorly differentiated PCa foci (Figure 3B), whereas the inner groups of cells mostly stained slight to negative (Figure $1 \mathrm{~B}$ and $3 \mathrm{E})$.

To determine whether these clusters "escape" DNA methylation of the SNAI2 gene promoter, detected in the majority of malignant epithelium, we carried out DNA sequencing in cells selectively microdissected from SNAI2 positive tumor edges versus those from the inner, SNAI2 negative, PCa foci with high Gleason grade. The SNAI2 gene proximal promoter region was persistently unmethylated in cell clusters from the edge, whereas it was methylated in those from the inner foci (Figure 2C). Further evidence is thus provided of the role suggested for this epigenetic mechanism in the heterogeneous regulation of $S N A I 2$ gene expression.
The Chromogranin-A (CHGA) positive NED areas (13 PCa samples containing NED areas), which may develop in conventional adenocarcinomas ( $\sim 10 \%$ frequency), especially within high-grade $\mathrm{PCa}$ (our observation and ref. 13), were marked by SNAI2 expression (Figure 3C), whose strength ranged from distinct to strong and involved nearly all cancer cells.

Moreover, immunohistochemical analysis of lymph node metastases in 15/102 PCa patients showed that they mostly (14/15) express SNAI2 with distinct to strong staining (Figure 3D).

Altogether, these observations lead us to assess whether knockdown of SNAI2 in PCa cells may affect the expression of genes shaping the NED or metastatic potential of PCa cells.

\section{SNAI2 regulates the expression of NED markers, metastasis-suppressor and pluripotency genes}

Since the $S N A I 2$ gene promoter was unmethylated in human PC3 cells, which clearly express SNAI2 mRNA, and protein at a level significantly $(p<0.05)$ higher than the 22Rv1 ( $\sim 13$ times), DU145 ( $\sim 38$ times) and LNCaP ( $\sim 2$ times) cell lines, we next performed, by specific small interfering RNA (siRNA), knockdown of SNAI2 in the PC3 line.

Treatment of PC3 cells with SNAI2-siRNA resulted in a significant $(p<0.05)$ reduction in the expression of both $S N A I 2$ mRNA (up to $80 \%, p<0.05$ ), and protein (by $84 \%$ adjusted to $\beta$-actin) in comparison to Control (Ctrl)siRNA treated cells, as determined, respectively by realtime RT-PCR and Western Blot analyses (Figure 4).

SNAI2-siRNA treatment did not affect expression of SNAI1 or other EMT-regulating transcription factors, including Zinc finger E-box-binding homeobox 1 (ZEB1) and 2 (ZEB2), TWIST1 and TWIST2 (not shown).

SNAI2 knockdown down-regulated Cyclin D1 by $54 \%$, with confirmation at the protein level, and modulated typical EMT cell surface markers such as E-Cadherin $(E-C a d h)$, which was up-regulated $(213 \%)$ and N-Cadherin $(\mathrm{N}-\mathrm{Cadh})$, which was slightly, but significantly $(p<0.05)$ down-regulated at the transcriptional $(76 \%)$ and protein level (Figure 4).

The neural tissue associated adhesion molecules, namely neuronal cell adhesion molecule (NrCAM) and $\mathrm{N}$-Cadherin 2 ( $\mathrm{N}$-Cadh 2), were dramatically down-regulated by $63 \%$ and $59 \%$ respectively at the transcriptional level with confirmation at the protein level (Figure 4), whereas the expression of neural cell adhesion molecule L1 (LICAM) remained unaltered.

Key genes for NED were clearly altered by SNAI2siRNA treatment since the expression of $C H G A$ was completely abolished and that of Enolase 2 (ENO2) significantly $(p<0.05)$ decreased, as revealed by real-time RT-PCR analyses (53\%), and confirmed at protein level by Western Blotting (Figure 4), while the expression of 
A

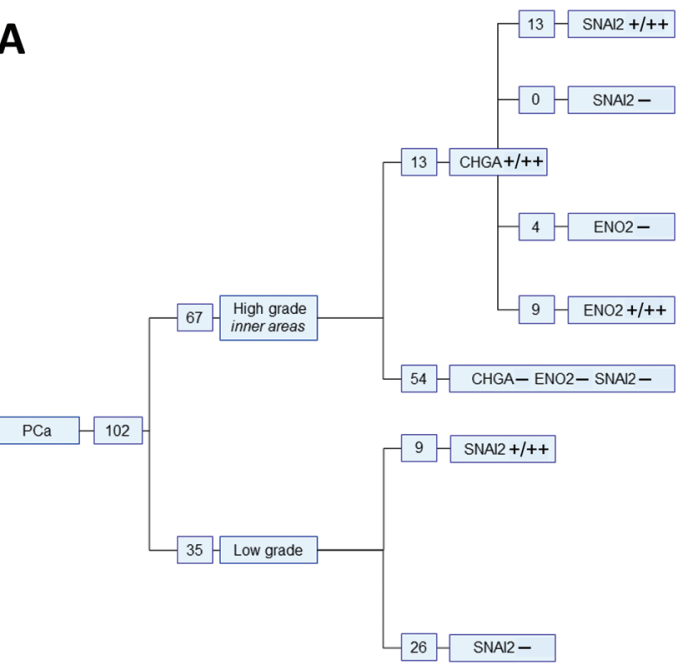

C

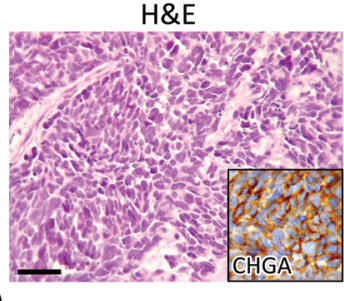

D

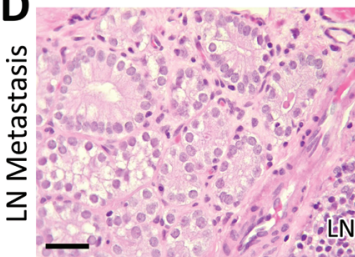

$\mathbf{E}$

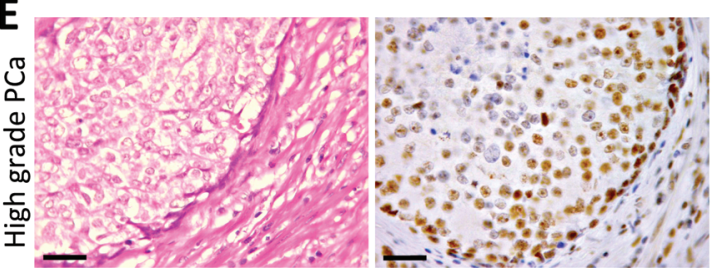

B
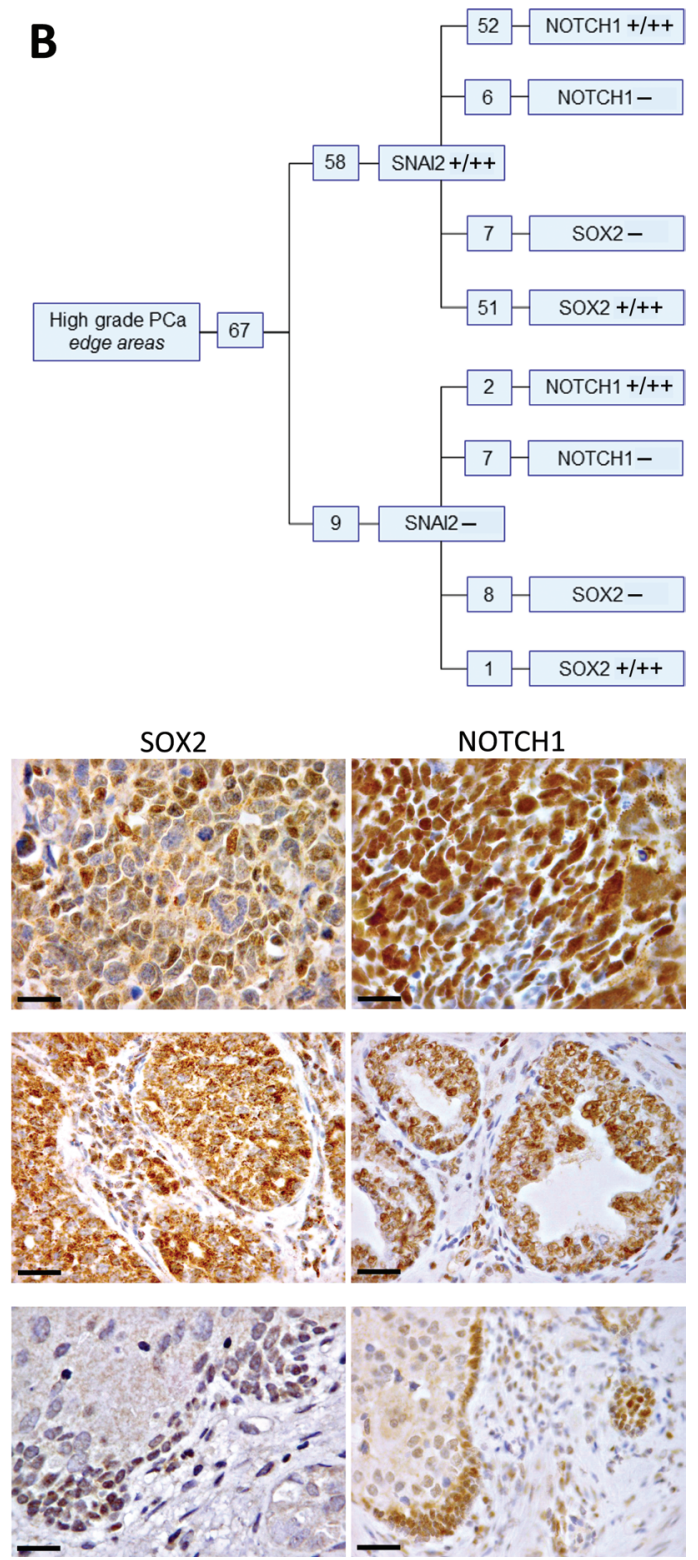

Figure 3: Immunohistochemical features of low- and high-grade foci in the primary PCa. (A) Distribution of SNAI2, CHGA and ENO2 expression in low-grade PCa, and in the inner areas of high-grade PCa. A total positive correlation was disclosed by Spearman's rank correlation coefficient between the expression of SNAI2 and CHGA in clinical high-grade PCa samples, whereas a high correlation was detected between SNAI2 and ENO2 expression $(\rho=0.8, p<0.0001)$. (B) Distribution of SNAI2, NOTCH1 and SOX2 expression at the edge of high-grade PCa. A positive relationship was disclosed, by Spearman's rank correlation coefficient, between the expression of SNAI2 and that of SOX2 $(\rho=0.63, p<0.0001)$ and NOTCH1 $(\rho=0.58, p<0.0001)$. (C) Immunohistochemical features of NED areas developed in conventional adenocarcinomas. Cancer cell nests forming CHGA+ (inset) NED areas firmly express SNAI2 (magnification X400) and SOX2, frequently NOTCH1 (magnification X630), with a distinct to strong staining. Scale bars: H\&E and SNAI2 staining, $30 \mu \mathrm{m} ;$ SOX2 and NOTCH1 staining, $20 \mu \mathrm{m}$. (D) Immunohistochemical features of lymph node metastases. Lymph node (LN) metastases frequently express SNAI2, SOX2 and NOTCH1, with a distinct to strong staining. Magnification X400. Scale bars: $30 \mu \mathrm{m}$. (E) Immunohistochemical features of high-grade PCa foci. Cancer cell clusters at the edge of high-grade PCa frequently express SNAI2, SOX2, and NOTCH1. Magnification X400. Scale bars: $30 \mu \mathrm{m}$.

synaptophysin $(S Y P)$ and neurogenic differentiation factor 1 (NeuroD1) only showed a trend towards down-regulation (not shown).

To assess whether SNAI2 may affect PCa cell malignancy by regulating other gene pathways besides those tightly associated with EMT, we next investigated the expression, in SNAI2 knockdown PC3 cells, of a set of metastasis-suppressor [17, 18] and pluripotency genes which have been associated with cancer aggressiveness and metastatic potential $[11,12]$.

Among the metastasis-suppressor genes, both $\mathrm{Nm} 23-\mathrm{HI}$ and KISSI were significantly $(p<0.05)$ up-regulated in SNAI2 knockdown PC3 cells, respectively by $337 \%$ and $209 \%$ at the transcriptional level, with confirmation at the protein 

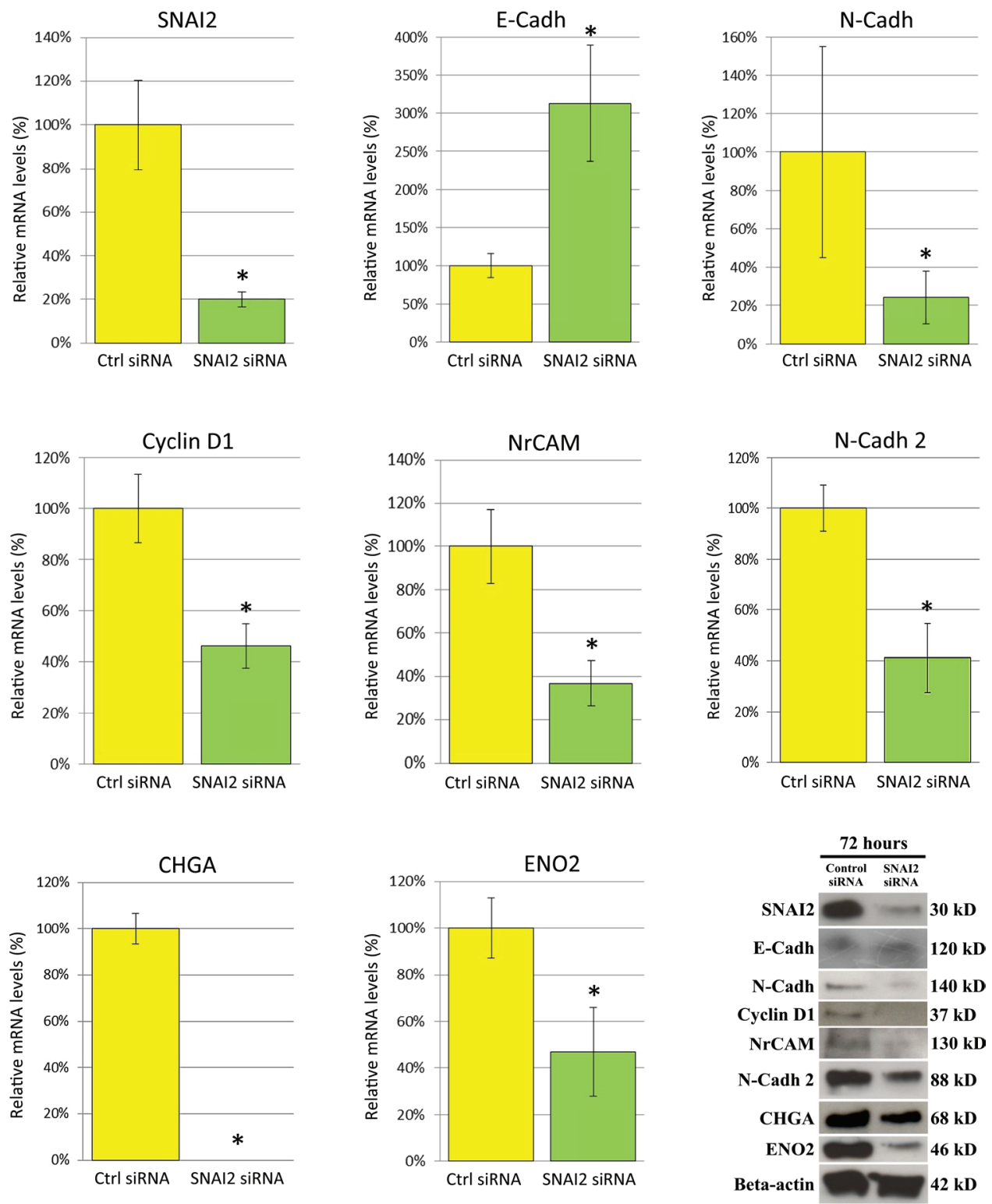

Figure 4: Effects of SNAI2-siRNA on the expression of genes associated to EMT, cell cycle, cell adhesion and neuroendocrine differentiation in PC3 cells, as assessed by real-time RT-PCR and Western Blot analysis. Real-time RT-PCR showed that SNAI2 mRNA expression in PC3 cells was silenced by $80 \%$ following 72 h of SNAI2-siRNA treatment. In SNAI2silenced PC3 cells, $E$-Cadh was remarkably up-regulated, whereas $\mathrm{N}$-Cadh was slightly, but significantly, down-regulated along with the Cyclin D1. The neural tissue associated adhesion molecules, $N r C A M$ and $N$-Cadh 2, and the neuroendocrine markers, CHGA and ENO2 were also considerably down-modulated in SNAI2-siRNA treated PC3 cells. Data are representative of three independent experiments. Western Blot analyses of Ctrl-siRNA and SNAI2-siRNA treated PC3 cells confirmed, at protein level, this gene expression regulation. $\beta$-actin was used as a loading control. * $p<0.05$ Student's $t$-test compared with Ctrl cells.

level (Figure 5), whereas the expression of CD82/KAI-1, phosphatidylethanolamine-binding protein 1/Raf kinase inhibitor protein $(P E B P 1 / R K I P)$, dual specificity mitogenactivated protein kinase $4(M A P 2 K 4)$ and 7 (MAP2K7) remained substantially unchanged.

SNAI2 knockdown also resulted in significant $(p<0.05)$ down-regulation of the expression levels of pluripotency and self-renewal associated genes such as SOX2 by $68 \%$, neurogenic locus notch homolog protein 1 (NOTCH1) by $80 \%, C D 44 v 6$ by $67 \%$ (Figure 5), octamer-binding transcription factor $4 \mathrm{~A}(O C T 4 A)$ by $88 \%$, and $N A N O G$ by $51 \%$, as assessed by real-time RT-PCR. These down-regulations were distinctly confirmed at the protein level for only the first three genes (Figure 5).

Expression levels of $S O X 9, B M I 1$, krueppel-like factor 4 (KLF4), C-MYC and sonic hedgehog ( $\mathrm{SHH})$ remained substantially unaltered.

Interestingly, the transcriptional regulators $\mathrm{WW}$ domain-containing transcription regulator protein 1/ transcriptional coactivator with PDZ-binding motif 

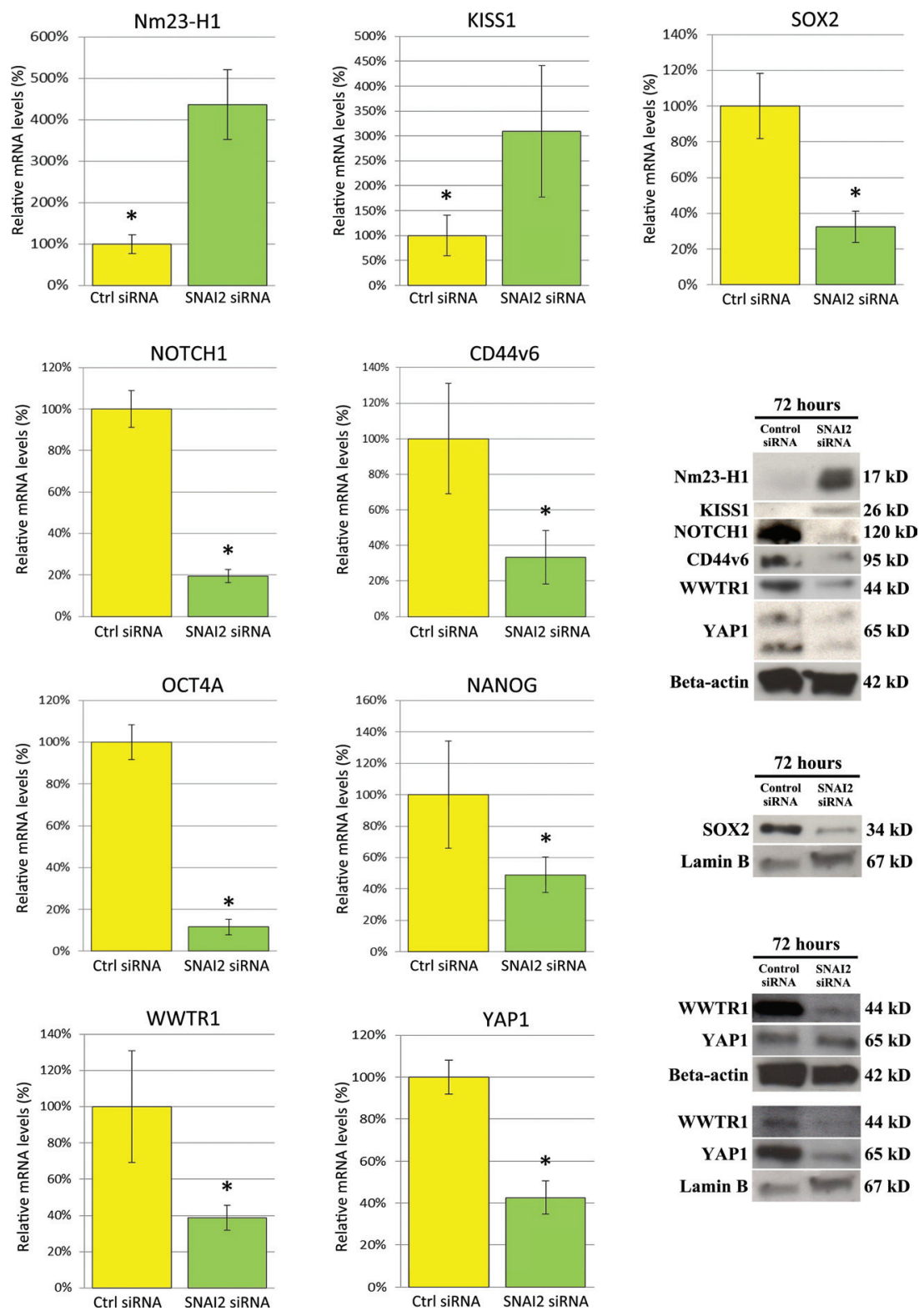

Figure 5: Effects of SNAI2-siRNA on the expression of metastasization- and pluripotency-associated genes in PC3 cells, as assessed by real-time RT-PCR and Western Blot analysis. Expression of Nm23-H1 and KISS1 was considerably up-regulated in PC3 cells after SNAI2-siRNA treatment. By contrast, the stemness-related genes CD44v6, SOX2, NOTCH1, along with WWTR1/TAZ, YAP1, OCT4A and NANOG were significantly down-regulated. Data are representative of three independent experiments. Western Blot analysis of Ctrl-siRNA and SNAI2-siRNA treated PC3 cells confirmed, at protein level, this gene expression regulation for only the first five genes, with $\beta$-actin or Lamin B (evaluation of the nuclear protein fractions of SOX2, WWTR1/TAZ and YAP1) as a loading control. $*_{p}<0.05$ Student's $t$-test compared with Ctrl cells.

$(W W T R 1 / T A Z)$ and Yes-associated protein 1 (YAP1), known to be involved in the self-renewal and metastatic properties of cancer cells [19, 20], were significantly $(p<0.05)$ down-regulated in SNAI2-siRNA treated cells in comparison with control cells, at the transcriptional level by $61 \%$ and $57 \%$ respectively, with confirmation at the protein level (Figure 5). Furthermore, distinct assessment of the nuclear (with Lamin B as a loading control) and cytoplasmic fractions of both TAZ and YAP1 proteins revealed that TAZ expression was down-regulated in both compartments and YAP1 substantially in the nuclei (Figure 5, bottom right WB images).

To confirm the finding of SNAI2-dependent regulation of genes governing NED, metastasization, and stemness, we finally transfected the SNAI2 gene into the DU145 cell line, which had revealed the lowest 
transcription level of endogenous SNAI2, and assessed expression levels of the above reported genes in $S N A I 2$ over-expressing cells.

DU145 cell transfection with SNAI2 expressing vector resulted in a significant $(p<0.05)$ increase in the expression of both SNAI2 mRNA (more than 90\%, $p<0.05$ ), and protein (by $259 \%$ adjusted to $\beta$-actin) in comparison with Ctrl-empty vector transfected cells, as determined, respectively by realtime RT-PCR and Western Blot analyses (Figure 6). Within the NED-related genes, $C H G A$ and $S Y P$ were up-regulated $(p<0.05)$ by $222 \%$, and $208 \%$ respectively (Figure 6 ), starting $24 \mathrm{~h}$ after DU145 cell transfection, whereas ENO2 only displayed a trend towards up-regulation (not shown). Within the stemness-related genes, the expression levels of SOX2, NOTCH1, and CD44v6, along with that of WWTR1/ $T A Z$, were significantly $(p<0.05)$ increased (by $183 \%$, $182 \%, 210 \%$, and $181 \%$, respectively) in SNAI2-overexpressing cells. A significant up-regulation of Cyclin D1 (by $227 \%$ ) was evidenced $48 \mathrm{~h}$ after cell transfection, whereas $24 \mathrm{~h}$ later, a significant $(p<0.05)$ down-regulation of the metastasis-suppressor gene KISS1, by $72 \%$, and of $\mathrm{CDH1}$, by $66 \%$, also occurred (Figure 6).
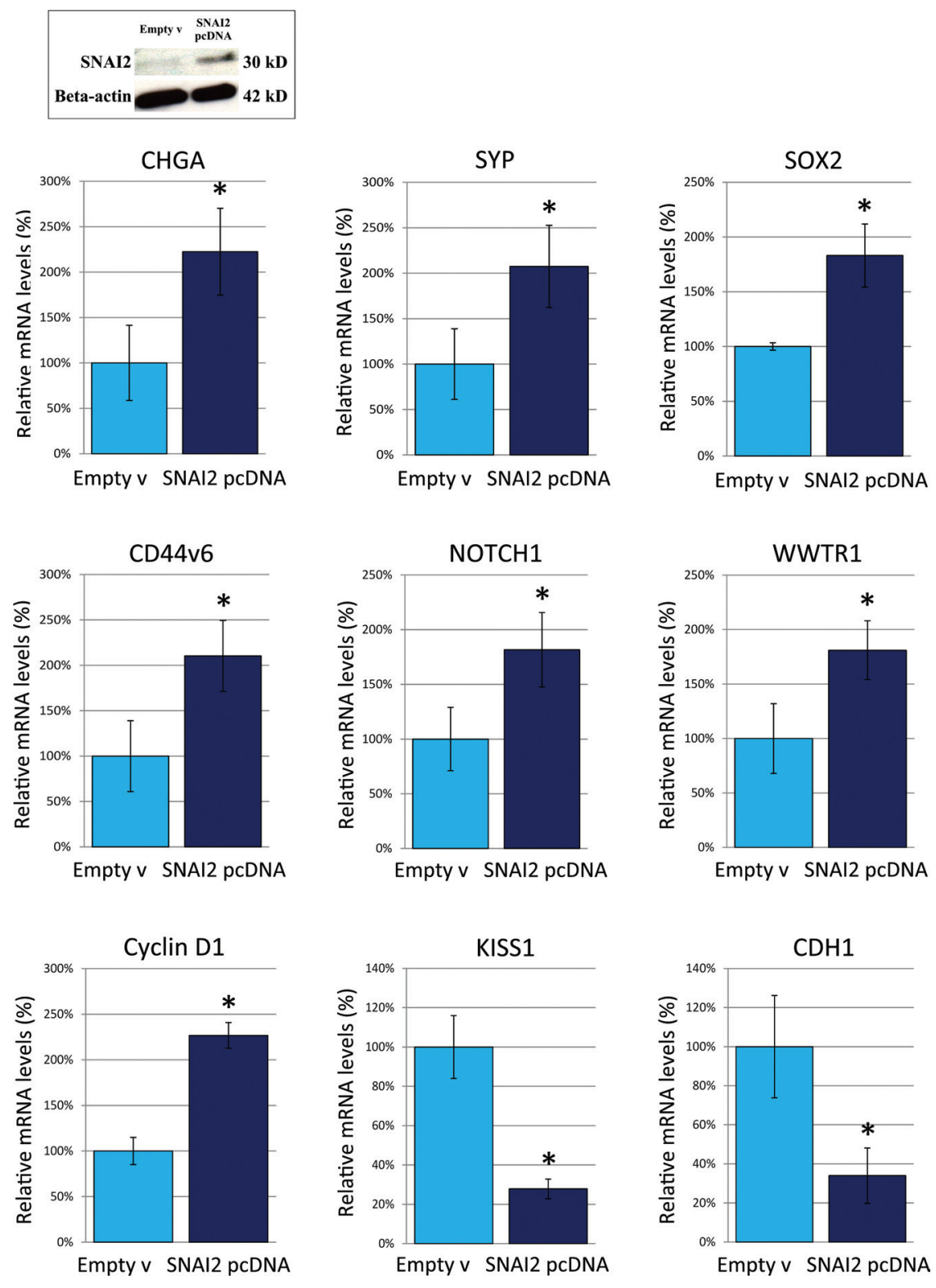

Figure 6: Effects of $\mathrm{SNAI2-gene} \mathrm{transfection} \mathrm{on} \mathrm{the} \mathrm{expression} \mathrm{of} \mathrm{neuroendocrine} \mathrm{differentiation-,} \mathrm{metastasization-}$ and pluripotency-associated genes in DU145 cells. Western Blot analyses showed that, in SNAI2-gene transfected DU145 cells, SNAI2 protein expression was up-regulated by $259 \%$ (adjusted to $\beta$-actin). Real-time RT-PCR showed that $C H G A$ and $S Y P$ were upregulated by $222 \%$, and $208 \%$, respectively. Within the stemness-related genes, the expression levels of SOX2, CD44v6 and NOTCH1, along with that of $W W T R 1 / T A Z$, increased by $183 \%, 210 \%, 182 \%$, and $181 \%$, respectively. Cyclin D1 was up-regulated by $227 \%$, whereas KISS 1 and $C D H 1$ were down-regulated by $72 \%$, and $66 \%$, respectively. ${ }^{*} p<0.05$ Student's $t$-test compared with Ctrl cells. 


\section{Expression of $S \mathrm{NAI} 2$ in clinical PCa samples was associated with that of the stemness-related transcription factors $\mathrm{SOX} 2$ and $\mathrm{NOTCH} 1$ and, with that of the NED-related genes $C H G A$ and ENO2}

Based on the evidence that SNAI2 silencing may substantially down-regulate $\mathrm{SOX} 2$ and $\mathrm{NOTCH1}$ expression, we immunohistochemically analysed patients' prostate tissue to assess the relationship between the expression of SNAI2 and that of these two down-stream target genes.

Real-time RT-PCR analyses of microdissected normal and neoplastic epithelium revealed that the mean levels of $\mathrm{SOX} 2$ and $\mathrm{NOTCH1}$ mRNA were considerably $(p<0.05)$ down-regulated in the neoplastic epithelial cell populations from both low- (SOX2: 65 times, NOTCH1: 7,5 times) and high- (11 times for both genes) grade $\mathrm{PCa}$ (with no appreciable difference between them) in comparison with the normal epithelium (Figure 7). Fluctuations of $\mathrm{SOX} 2$ and NOTCH1 expression from one sample to another were associated with those of SNAI2 $(r=0.69$ for $S O X 2 ; r=0.51$ for NOTCH1), resulting in a mean $\pm \mathrm{SD}$ of SOX2 and NOTCH1 expression levels that paralleled, in the epithelium, SNAI2 expression levels.

Furthermore, in accordance with the heterogeneity of SNAI2 expression in the primary PCa, the strength of

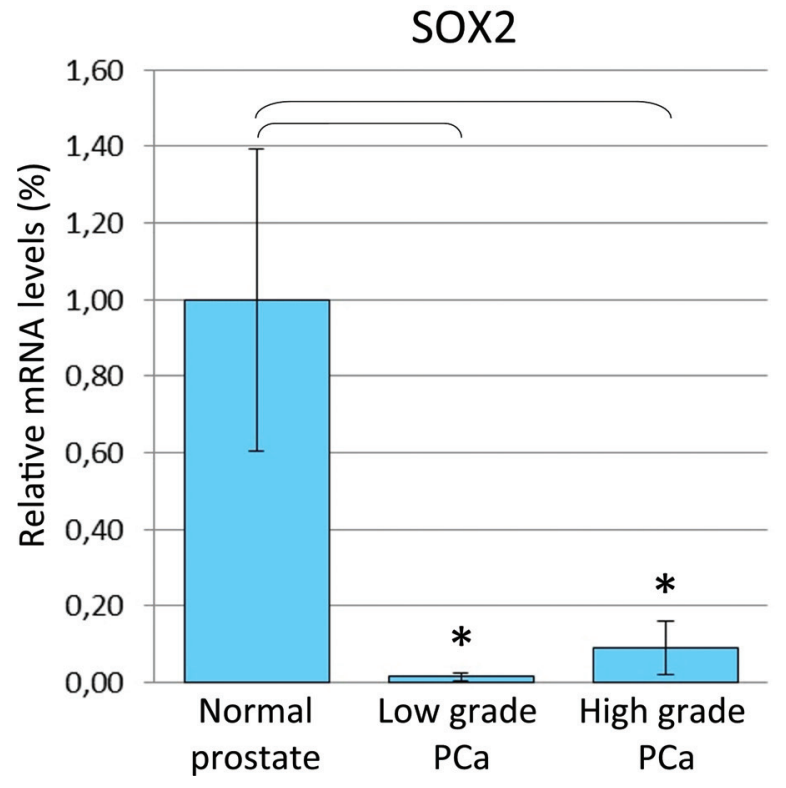

the staining of both SOX2 and NOTCH1 was frequently distinct or strong in the tumor cell clusters forming the expansion/invasion front of high-grade $\mathrm{PCa}$ foci (Figure 3B and 3E).

In particular, SNAI2 staining was shown at the edge of 58/67 high-grade PCa foci. 51 out of 58 SNAI2 positive tumor edges also stained for SOX2 and 52/58 also stained for NOTCH1 (Figure 3B). Concomitant expression of all three markers was found at the edge of 50/67 highgrade PCa foci (Figure 3B). Spearman's rank correlation coefficient disclosed a positive relationship between the expression of SNAI2 and those of SOX2 $(\rho=0.63$, $p<0.0001)$ and NOTCH1 $(\rho=0.58, p<0.0001)$.

Furthermore, immunohistochemical analysis of lymph node metastases revealed distinct to strong SOX2 and NOTCH1 expression in 11/15 and 12/15 metastatic lesions, respectively (Figure 3D).

Lastly, all the 13 NED areas in our sample collection were marked by distinct to strong SOX2 expression (Figure 3C), and 11/13 also showed a distinct to strong NOTCH1 expression, involving nearly all cancer cells (Figure 3C).

As to the relationship between SNAI2 and NEDrelated gene expression, a total positive correlation emerged between the expression of SNAI2 and CHGA in clinical high-grade PCa samples, since all the 13 CHGApositive NED areas also expressed SNAI2, whereas

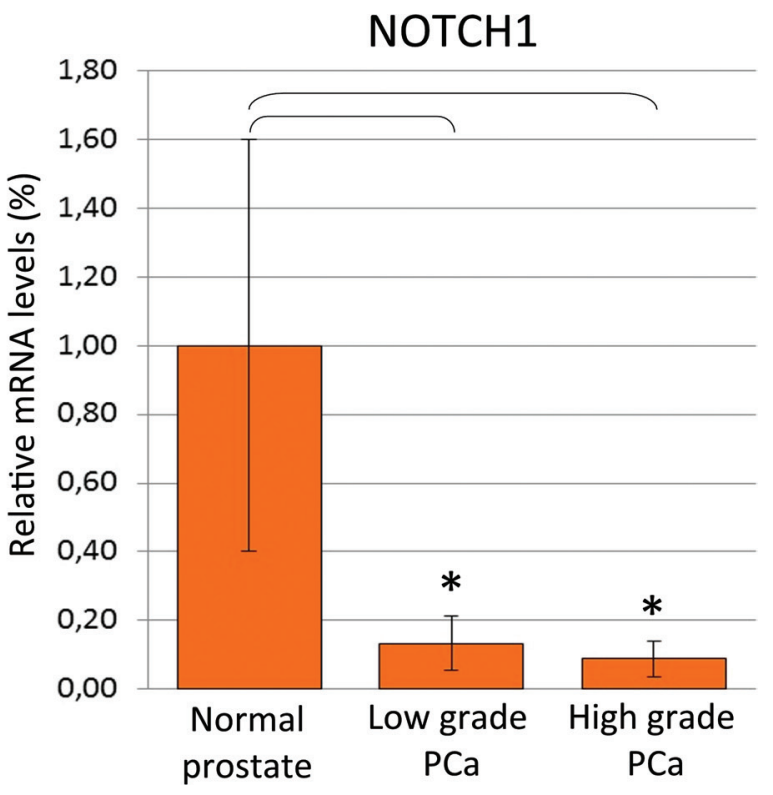

Figure 7: SOX2 and NOTCH1 mRNA expression in normal and cancerous prostate epithelium from PCa patients. (A) Histogram representing the relative expression $\pm \mathrm{SD}$ of SOX2 mRNA in microdissected histologically normal epithelium and its neoplastic counterparts with low or high Gleason grades, from prostatectomized patients (groups of 15), normalized with the housekeeping gene HPRT. One-way ANOVA for comparisons between epithelial compartments of normal prostate, low- and high-grade PCa: $p<0.0001 .{ }^{*} p<0.01$ Tukey HSD Test compared with normal prostate epithelium. (B) Histogram representing the relative expression \pm SD of $N O T C H 1$ mRNA in microdissected histologically normal epithelium and its neoplastic counterparts with low or high Gleason grades, from prostatectomized patients (groups of 15), normalized with the housekeeping gene HPRT. One-way ANOVA for comparisons between epithelial compartments of normal prostate, low- and high-grade PCa: $p<0.0001 .{ }^{*} p<0.01$ Tukey HSD Test compared with normal prostate epithelium. 
the 54 CHGA-negative high-grade PCa lacked SNAI2 expression (apart from the tumor burden) (Figure 3A and 3C). In addition, a high correlation, was detected between SNAI2 and ENO2 expression, $\rho=0.8, p<0.0001$, since a distinct to strong ENO2 expression involved 9/13 NED areas, whereas it was absent in the 54 SNAI2-negative high-grade PCa (Figure 3A).

\section{DISCUSSION}

This study sheds new light on the role of the SNAI2 gene in the pathogenesis and progression of $\mathrm{PCa}$ in function of the heterogeneous nature of this disease. Here we report, for the first time, that $\mathrm{PCa}$ is marked by the transcriptional silencing of SNAI2 in most of the neoplastic epithelium, irrespective of its differentiation grade, in association with gene promoter methylation. This epigenetic silencing appears to be quite selective since it does not involve NED areas and invasion fronts of high-grade tumors. The basal cell loss distinctive of malignant prostatic glands [15] is not responsible for the loss of SNAI2 expression in $\mathrm{PCa}$, as shown by the comparable levels of SNAI2 transcript within basal cells, more differentiated luminal secretory cells, and the whole glandular epithelium, which also means that, in the normal prostatic epithelium, $S N A I 2$ expression is unrelated to the different self-renewal capabilities of the cell compartments.

The finding of a substantial SNAI2 down-modulation in neoplastic as compared to normal prostate epithelia agrees with data obtained by gene expression profiling of $\mathrm{PCa}$ samples, by Urbanucci et al. [21], and of microdissected PCa epithelia, by Tomlins et al [22]. A similar unexpected finding has recently been described in melanoma development $[23,24]$ suggesting that SNAI2's role in the pathogenesis of cancer goes beyond its well-known EMT regulation. Our data reveal that, in addition to the canonical cadherin switch, represented by the opposite E-Cadh/NCadh expression, and Cyclin D1 regulation, which confirms its influence on the cell cycle [25], SNAI2 heavily affects the expression of the neural tissue associated adhesion molecules N-Cadh 2 and Nr-CAM both critically involved in cell migration and invasion and strongly down-regulated in PCa cells following SNAI2 silencing.

Above all, our study shows that SNAI2 may condition prostate carcinogenesis as an up-stream regulator of multiple cancer progression pathways governed by pluripotency-, neuroendocrine- or metastasization-related gene. It also lends support to recent efforts to develop SNAI2-targeting drugs [26, 27].

SNAI2 gene dramatically modulates three key regulators of the cell stem state, associated with invasion and metastasization, namely CD44v6 [28, 29], SOX2 [30-34] and NOTCH1 [35-38], as revealed by both SNAI2 silencing and over-expression experiments, in PCa cells in vitro and, probably, in $\mathrm{PCa}$ tissue in vivo. The topographic distribution of SOX2 and NOTCH1 expression, in fact, is closely related to that of SNAI2, thus strengthening the idea that, as downstream targets, their expression may be boosted by SNAI2 in selected PCa areas, namely; a. cell clusters at the invasive front of poorly differentiated, high-grade, PCa foci, b. NED areas developed in their context, and c. lymph node metastases. The frequency of their concomitant expression in these sites strongly suggests their cooperation in promoting $\mathrm{PCa}$ progression.

As emerging regulators of cancer stemness, growth and malignant progression, the two closely related transcriptional regulators YAP1 and TAZ are drastically down-modulated by $S N A I 2$ gene silencing, whereas TAZ in particular is also up-regulated by SNAI2 overexpression. TAZ is required to sustain self-renewal and tumor-initiation capacities in breast cancer stem cells $[20,39]$. It is turned on by over-expression of the EMTinducing transcription factors TWIST or Snail [20], and is required for TWIST-induced self-renewal. TAZ itself can sustain EMT [20, 40]. Nuclear localization promotes TAZ/YAP1 transcriptional activity driving cell proliferation, transformation and tumorigenicity [41]. Our present demonstration of a significant decrease in the nuclear fraction of TAZ and particularly YAP1 proteins following SNAI2 silencing suggests that SNAI2 regulates not only their expression, but also their translocation and transcriptional activation. The TAZ/YAP1 system may thus be proposed as a novel key downstream effector of SNAI2's function in PCa. Similarly, the metastasissuppressors Nm23-H1 and, particularly, KISS1 have been revealed as downstream effectors of SNAI2's prometastatic role, since expression of both greatly increases following SNAI2 knockdown, whereas SNAI2 overexpression substantially down-regulates the KISS1 gene expression only. The mechanisms whereby Nm23-H1 and KISS1 exert metastasis-suppressor functions involve multiple pathways and are not completely clear [42, 43]. Their reduced expression, however, is associated with increased cancer cell invasiveness, metastasization and a poorer clinical outcome in most tumor types, including $\mathrm{PCa}$, while their over-expression hinders cancer cell migration and invasion [44, 45].

As a hallmark of PCa aggressiveness, NED has been associated with tumor progression and development of castration-resistant disease [13, 14]. Normal prostatic neuroendocrine cells are thought to be derived from the neural crest during embryogenesis [46]. SNAI2 drives their migration [4], and has been described as a neural crest and neural plate border marker [47, 48]. We show that SNAI2 gene silencing abolishes the expression of $C H G A$ and dramatically reduces that of ENO2, whereas its over-expression substantially up-regulates $C H G A$ and $S Y P$ expression. These data are in line with the finding of a tight correlation between expression of NED markers and that of SNAI2 in the clinical samples, and suggest that firm and strong SNAI2 expression promotes NED within 
high-grade $\mathrm{PCa}$, thus favoring tumor progression along these pathways [14]. Our present assessment of the involvement of SNAI2 in a variety of malignancy-related gene pathways, has not disclosed a complete SNAI2-associated gene expression profile in the clinical samples, achievable by DNA microarray or next generation sequencing, and its correlation with the follow-up. This limitation may be overcome in the event of a future substantial increase in patient recruitment and biological sample collection.

Taken as a whole our findings provide novel insight into the complex molecular heterogeneity of $\mathrm{PCa}$, and lead to the following conclusions:

I. An aberrant and selective regulation of SNAI2 expression marks the growth and progression of $\mathrm{PCa}$, since it is lacking in the former and clearly present in the latter.

II. Silencing of SNAI2 in most PCa epithelia may turn off the expression of NED markers and pluripotency genes while turning on that of specific metastasis-suppressor genes.

III. Selective SNAI2 expression in cancer cell clusters at the invasion front, or in NED areas of poorly differentiated PCa may endow these cells with stemness and/ or neuroendocrine traits and migration/invasion property, thus promoting their self-renewal and metastatic capabilities.

These conclusions strongly identify the SNAI2 gene as a key target for modern strategies to prevent or cure the metastatic disease.

\section{MATERIALS AND METHODS}

\section{Ethics statement}

Investigation has been conducted in accordance with the ethical standards and according to the Declaration of Helsinki and according to national and international guidelines and has been approved by the authors' institutional review board.

\section{Patients and samples}

We collected tissue samples, and the clinical and pathological data of 102 patients aged 58-73 treated by radical prostatectomy for $\mathrm{PCa}$.

PCa samples were graded [49] as Gleason score $5(n=18), 6(n=14), 7(n=32), 8(n=27)$, and 9 $(n=11)$ and staged [50] as pT2, organ-confined cancer ( $n=58$ [13 T2aN0M0, 22 T2bN0M0, 18 T2cN0M0, and 5 T2cN1M0]) and pT3, capsular penetration $(n=44$ [19 T3aN0M0, 4 T3aN1M0, 15 T3bN0M0, and 6 T3bN1M0]). On the bases of pathological TNM classification, the cases were divided into: 53 in Stage II, 34 in Stage III and 15 in Stage IV (with metastases to the pelvic lymph nodes). In addition, we obtained normal prostates (histologically negative for PCa or benign prostatic hyperplasia) from 16 untreated patients, aged 55-64, prostatectomized for bladder cancer (control patients). Sample collection and processing are described in the online Supporting Information.
Written informed consent was obtained from patients. The study has been approved by the Ethical Committee of the "G. d'Annunzio" University of Chieti (Italy), and Local Health Authority No. 2 in PROT 1945/09 COET of 14/07/2009, and performed in accordance with the principles outlined in the Declaration of Helsinki.

\section{Laser capture microdissection}

For LCM, $10 \mu \mathrm{m}$ frozen sections (two sections per sample) from cancer and normal prostate specimens (of both control and PCa patients) were analyzed.

Neoplastic foci with low Gleason grade were obtained from 35/102 PCa patients, whereas those with high grade were obtained from the other 67/102 PCa patients.

Epithelial and stromal components were dissected from cancer and normal prostate specimens as described in the online Supporting Information.

\section{Methylation analysis by bisulfite genomic sequencing}

Genomic DNA was extracted from microdissected cells using the QIAamp DNA Micro Kit and then bisulfiteconverted with the EpiTect Bisulfite Conversion Kit (both from Qiagen, Hilden, D).

The sequence reaction was performed with BigDye $^{\circledR}$ Terminator v3.1 Cycle Sequencing Kit (Applied Biosystems, Foster City, CA, USA) with the primers used for the PCR reaction.

The sequence products were separated on a fluorescent capillary sequencer (ABI 3130xl, Applied Biosystems) and analyzed with SeqScape software (Applied Biosystems). Details on the sequence reaction and the primers used are described in the online Supporting Information.

\section{Immunohistochemistry}

Single and double Immunohistochemistry on formalin-fixed, paraffin-embedded samples was performed as described in the online Supporting Information.

\section{The Morphometric analyses}

SNAI2, CHGA, ENO2, SOX2 and NOTCH1 expression by primary tumors or lymph node metastases was evaluated using the following criteria based on 1) the widening of the staining expressed as the percentage of tumor or metastasis stained i.e.: $<50 \%, \geq 50 \% \leq 70 \%$, and $>70 \%$, and 2 ) the strength of the staining: defined as negative (0), slight (1), moderate (2) or intense (3).

Thus, immunostaining was defined as:

strong ++ , when a) the widening was $>70 \%$ and its strength range slight (1) to intense (3), or b) the widening was $>50 \% \leq 70 \%$ and its strength range moderate (2) to intense (3); 
distinct + , when a) the widening was $>50 \% \leq 70 \%$ and its strength was slight (1) or b) the widening was = $50 \%$ and its strength range slight (1) to intense (3);

absent - , when the widening was $<50 \%$ and its strength was slight (1) to negative (0).

Results were expressed as the percentage of positive cells, or as the mean \pm SD of positive cells/field, evaluated by light microscopy on single immunostained formalin-fixed paraffin-embedded sections at X400 in a $85431.59 \mu^{2}$ field.

Six to 10 high-power fields (depending on the tumor width) were examined per section and three sections per sample were evaluated.

Stained sections were examined by two pathologists (EDC and $\mathrm{CS}$ ) in a blind fashion, with very good agreement $(\kappa$ value $=0.82)$ [51]

\section{Cell cultures, $S N A I 2$ silencing and over-expression}

The human PCa cell lines 22Rv1, DU145, LNCaP (from the American Type Culture Collection, Manassas, VA, USA) and PC3 (Interlab Cell Line Collection, CBA/ IST San Martino, Genova Italy), were cultured in RPMI 1640 with $10 \%$ FCS. Cell lines were obtained directly from the above mentioned cell banks that performed cell line characterizations by Short Tandem Repeats (STR) profile analysis. PC3, 22Rv1, DU145 and LNCaP were passaged in our laboratory for fewer than 6 months after resuscitation.

RNA was extracted using RNeasy Mini Kit (Qiagen) and subjected to real-time RT-PCR, to detect SNAI2 mRNA expression levels, by the RT ${ }^{2}$ First Strand cDNA Synthesis kit (SABioscience, Frederick, MD, USA).

Silencing of human $S N A I 2$ was achieved by transfection of 1 x $10^{6}$ PC3 cells with lipofectamine RNAiMax reagent (Life Technologies, Carlsbad, CA, USA) using $3 \mu \mathrm{g}$ of Mission esiRNA SNAI2 or irrelevant siRNA Universal Negative Control (Sigma-Aldrich, St. Louis, MO, USA).

RNA was extracted after 72 hours and subjected to real-time RT-PCR. Furthermore, cell pellets from PC3 cells were collected for Western Blotting.

For overexpression of SNAI2 in DU145 cells, the GFPtagged SNAI2 expression vector or empty vector (pCMV6AC-GFP) (both from OriGene Technologies, Rockville, MD, USA) was transfected into 1 x $10^{6}$ cells using lipofectamine RNAiMax reagent (Life Technologies).

Twenty-four, 48, and 72 hours after DU145 cell transfection, RNA was extracted and subjected to real-time RT-PCR, and cell pellets were collected for Western Blotting.

\section{Real-time RT-PCR}

The real-time RT-PCR was performed on RNA extracted from microdissected cells and SNAI2-silenced and Ctrl cells, using the Quantitect Reverse Transcription Kit for the reverse transcription and the QuantiFast SYBR Green PCR Kit for real-time PCR (both from Qiagen). The real-time RT-PCR was done, with primers listed in the online Supporting Information using the MiniOpticon System (Bio-Rad, Hercules, CA, USA).

\section{Western blotting}

Western blot was performed using total proteins and nuclear extracts obtained from approximately $2.0 \times 10^{6}$ cells. Cells were collected following standard procedures. Then, $1.0 \mathrm{~mL}$ of ice cold RIPA Lysis buffer (Thermo Scientific, Waltham, MA, USA) was added, with freshly added Protease and Phosphatase Inhibitors Cocktails (Thermo Scientific). SOX2, WWTR1/TAZ and YAP1 were investigated in nuclear fractions, obtained using CelLytic ${ }^{\mathrm{TM}}$

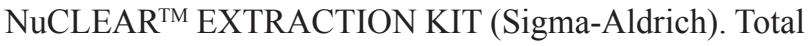
proteins and nuclear fractions were measured in the extract by the Bradford assay.

The nuclear fractions and the whole cell lysates were examined on Mini-PROTEAN TGX Gels 4-20\% (Bio-Rad). Proteins were transferred from gels on ImmunBlot PVDF Membranes (Bio-Rad) in the transfer buffer (glycine, tris [pH 8.4] and methanol) using Mini Trans-Blot Cell apparatus (Bio-Rad). Membranes containing proteins were blocked with milk 5X (Sigma-Aldrich) in TBST and, subsequently, probed with primary and horseradish peroxidase conjugated secondary antibodies following standard procedures. Proteins transferred membranes were washed with TBST and developed with Pierce ECL Western Blotting Substrate (Thermo Scientific). Details are provided in the online Supporting Information.

\section{Statistical analysis}

Between-group differences in the relative expression of SNAI2, SOX2 or NOTCH1, by real-time RT-PCR, in epithelial or stromal compartments of normal and neoplastic prostate tissues were assessed by ANOVA. The difference between each pair of means was evaluated with the Tukey HSD test. Differences in the relative gene expression, by real-time RTPCR, between SNAI2-silenced, SNAI2-overexpressing and Ctrl cells were assessed by Student's $t$-test. The $\chi 2$ test and the Mann-Whitney U probability test were used to examine the association between SNAI2 expression levels and the clinical and pathologic characteristics. The Spearman's rank correlation coefficient $(\rho)$ was used to examine the correlation between SNAI2 protein expression and immunohistochemical staining for SOX2, NOTCH1, CHGA, and ENO2 whereas the Pearson product-moment correlation coefficient $(r)$ was used to examine the correlation between mRNA expression levels of SOX2 or NOTCH1 and SNAI2. The SPSS software, version 11.0 (IBM, Armonk, NY, USA) was employed, with $p<0.05$ as the significance cut-off.

\section{ACKNOWLEDGEMENTS}

This work was supported by grants from the Associazione Italiana Ricerca sul Cancro (AIRC, Investigator Grant n. 13134) and the "Umberto Veronesi" 
Foundation for the Progress of Sciences to E. Di Carlo; and grants from AIRC (Investigator Grant n. 13018), Ricerca Finalizzata Collaboratore Estero, Ministero della Salute (Grant n. RF-2010-2308270), and from Cinque per mille e Ricerca Corrente, Ministero della Salute to I. Airoldi.

\section{CONFLICTS OF INTEREST}

The authors disclose no potential conflicts of interest.

\section{REFERENCES}

1. Cobaleda C, Pérez-Caro M, Vicente-Dueñas C, SánchezGarcía I. Function of the zinc-finger transcription factor SNAI2 in cancer and development. Annu Rev Genet. 2007; 41:41-61.

2. Nieto MA, Cano A. The epithelial-mesenchymal transition under control: global programs to regulate epithelial plasticity. Semin Cancer Biol. 2012; 22:361-368.

3. Stegmann K, Boecker J, Kosan C, Ermert A, Kunz J, Koch MC. Human transcription factor SLUG: mutation analysis in patients with neural tube defects and identification of a missense mutation (D119E) in the Slug subfamilydefining region. Mutat Res. 1999; 406:63-69.

4. Nieto MA, Sargent MG, Wilkinson DG, Cooke J. Control of cell behavior during vertebrate development by Slug, a zinc finger gene. Science. 1994; 264:835-839.

5. Hemavathy K, Ashraf SI, Ip YT. Snail/slug family of repressors: slowly going into the fast lane of development and cancer. Gene. 2000; 257:1-12.

6. Inukai $\mathrm{T}$, Inoue $\mathrm{A}$, Kurosawa $\mathrm{H}$, Goi $\mathrm{K}$, Shinjyo $\mathrm{T}$, Ozawa K, Mao M, Inaba T, Look AT. SLUG, a ces-1-related zinc finger transcription factor gene with antiapoptotic activity, is a downstream target of the E2A-HLF oncoprotein. Mol Cell. 1999; 4:343-352.

7. Pérez-Mancera PA, González-Herrero I, Pérez-Caro M, Gutiérrez-Cianca $\mathrm{N}$, Flores $\mathrm{T}$, Gutiérrez-Adán A, Pintado B, Sánchez-Martín M, Sánchez-García I. SLUG in cancer development. Oncogene. 2005; 24:3073-3082.

8. Uygur B, Wu WS. SLUG promotes prostate cancer cell migration and invasion via CXCR4/CXCL12 axis. Mol Cancer. 2011; 10:139.

9. Augello MA, Burd CJ, Birbe R, McNair C, Ertel A, Magee MS, Frigo DE, Wilder-Romans K, Shilkrut M, Han S, Jernigan DL, Dean JL, Fatatis A, et al. Convergence of oncogenic and hormone receptor pathways promotes metastatic phenotypes. J Clin Invest. 2013; 123:493-508.

10. Guo W, Keckesova Z, Donaher JL, Shibue T, Tischler V, Reinhardt F, Itzkovitz S, Noske A, Zürrer-Härdi U, Bell G, Tam WL, Mani SA, van Oudenaarden A, et al. Slug and Sox 9 cooperatively determine the mammary stem cell state. Cell. 2012 Mar 2. 148:1015-1028.

11. Pece S, Tosoni D, Confalonieri S, Mazzarol G, Vecchi M, Ronzoni S, Bernard L, Viale G, Pelicci PG, Di Fiore PP.
Biological and molecular heterogeneity of breast cancers correlates with their cancer stem cell content. Cell. 2010; 140:62-73.

12. Hayashida $\mathrm{T}$, Jinno $\mathrm{H}$, Kitagawa $\mathrm{Y}$, Kitajima $\mathrm{M}$. Cooperation of cancer stem cell properties and epithelialmesenchymal transition in the establishment of breast cancer metastasis. J Oncol. 2011; 591427.

13. Bonkhoff $\mathrm{H}$. Neuroendocrine differentiation in human prostate cancer. Morphogenesis, proliferation and androgen receptor status. Ann Oncol. 2001; 12:S141-4.

14. Komiya A, Suzuki H, Imamoto T, Kamiya N, Nihei N, Naya Y, Ichikawa T, Fuse H. Neuroendocrine differentiation in the progression of prostate cancer. Int J Urol. 2009; 16:37-44.

15. Rosai J. Male reproductive system. In: Rosai J. Rosai and Ackerman's Surgical Pathology (10th edition). London: Elsevier). 2011;1287-1288.

16. Kim JH, Dhanasekaran SM, Prensner JR, Cao X, Robinson D, Kalyana-Sundaram S, Huang C, Shankar S, Jing X,Iyer M, Hu M, Sam L, Grasso C, et al. Deep sequencing reveals distinct patterns of DNA methylation in prostate cancer. Genome Res. 2011; 21:1028-1041.

17. Steeg PS, Ouatas T, Halverson D, Palmieri D, Salerno M. Metastasis suppressor genes: basic biology and potential clinical use. Clin Breast Cancer. 2003; 4:51-62.

18. Thiolloy S, Rinker-Schaeffer CW. Thinking outside the box: using metastasis suppressors as molecular tools. Semin Cancer Biol. 2011; 1:89-98.

19. Cordenonsi M, Zanconato F, Azzolin L, Forcato M, Rosato A, Frasson C, Inui M, Montagner M, Parenti AR, Poletti A, Daidone MG, Dupont S, Basso G, et al. The Hippo transducer TAZ confers cancer stem cell-related traits on breast cancer cells. Cell. 2011; 147:759-772.

20. Chan SW, Lim CJ, Guo K, Ng CP, Lee I, Hunziker W, Zeng Q, Hong W. A role for TAZ in migration, invasion, and tumorigenesis of breast cancer cells. Cancer Res. 2008; 68:2592-2598.

21. Urbanucci A, Sahu B, Seppälä J, Larjo A, Latonen LM, Waltering KK, Tammela TL, Vessella RL, Lähdesmäki H, Jänne OA, Visakorpi T, et al. Overexpression of androgen receptor enhances the binding of the receptor to the chromatin in prostate cancer. Oncogene. 2012; 26:2153-2163.

22. Tomlins SA, Mehra R, Rhodes DR, Cao X, Wang L, Dhanasekaran SM, Kalyana-Sundaram S, Wei JT, Rubin MA, Pienta KJ, Shah RB, Chinnaiyan AM. Integrative molecular concept modeling of prostate cancer progression. Nat Genet. 2007; 39:41-51.

23. Shirley SH, Greene VR, Duncan LM, Torres Cabala CA, Grimm EA, Kusewitt DF. Slug expression during melanoma progression. Am J Pathol. 2012; 180:2479-2489.

24. Koefinger P, Wels C, Joshi S, Damm S, Steinbauer E, Beham-Schmid C, Frank S, Bergler H, Schaider H. The cadherin switch in melanoma instigated by HGF is mediated through epithelial-mesenchymal transition regulators. Pigment Cell Melanoma Res. 2011; 24:382-385. 
25. Olmeda D, Montes A, Moreno-Bueno G, Flores JM, Portillo F, Cano A. Snai1 and Snai2 collaborate on tumor growth and metastasis properties of mouse skin carcinoma cell lines. Oncogene. 2008; 27:4690-4701.

26. Ding G, Feng C, Jiang H, et al. Combination of Rapamycin, CI-1040, and 17-AAG Inhibits Metastatic Capacity of Prostate Cancer via Slug Inhibition. PLoS ONE. 2013; 8:e77400.

27. Little GH, Baniwal SK, Adisetiyo H, Groshen S, Chimge NO, Kim SY, Khalid O, Hawes D, Jones JO, Pinski J, Schones DE, Frenkel B. Differential effects of RUNX2 on the androgen receptor in prostate cancer: synergistic stimulation of a gene set exemplified by SNAI2 and subsequent invasiveness. Cancer Res. 2014; 15:2857-2868.

28. Ghatak S, Hascall VC, Markwald RR, Misra S. Stromal hyaluronan interaction with epithelial CD44 variants promotes prostate cancer invasiveness by augmenting expression and function of hepatocyte growth factor and androgen receptor. J Biol Chem. 2010; 285:19821-19832.

29. Ni J, Cozzi PJ, Hao JL, Beretov J, Chang L, Duan W, Shigdar S, Delprado WJ, Graham PH, Bucci J, Kearsley JH, Li Y. CD44 variant 6 is associated with prostate cancer metastasis and chemo-/radioresistance. Prostate. 2014; 74:602-617.

30. Park IH, Zhao R, West JA, Yabuuchi A, Huo H, Ince TA, Lerou PH, Lensch MW, Daley GQ. Reprogramming of human somatic cells to pluripotency with defined factors. Nature. 2008; 451:141-146.

31. Chambers I, Tomlinson SR. The transcriptional foundation of pluripotency. Development. 2009; 136:2311-2322.

32. Liu K, Lin B, Zhao M, Yang X, Chen M, Gao A, Liu F, Que J, Lan X. The multiple roles for Sox 2 in stem cell maintenance and tumorigenesis. Cell Signal. 2013; 25:1264-1271.

33. Jia X, Li X, Xu Y, Zhang S, Mou W, Liu Y, Liu Y, Lv D, Liu CH, Tan X, Xiang R, Li N. SOX2 promotes tumorigenesis and increases the anti-apoptotic property of human prostate cancer cell. J Mol Cell Biol. 2011; 3:230-238.

34. Kong D, Banerjee S, Ahmad A, Li Y, Wang Z, Sethi S, Sarkar FH. Epithelial to mesenchymal transition is mechanistically linked with stem cell signatures in prostate cancer cells. PloS One. 2010; 5:e12445.

35. Pannuti A, Foreman K, Rizzo P, Osipo C, Golde T, Osborne B, Miele L. Targeting Notch to target cancer stem cells. Clin Cancer Res. 2010; 16:3141-3152.

36. Zhu H, Zhou X, Redfield S, Lewin J, Miele L. Elevated Jagged-1 and Notch-1 expression in high grade and metastatic prostate cancers. Am J Transl Res. 2013; 5:368-378.

37. Domingo-Domenech J, Vidal SJ, Rodriguez-Bravo V, Castillo-Martin M, Quinn SA, Rodriguez-Barrueco R, Bonal DM, Charytonowicz E, Gladoun N, de la IglesiaVicente J, Petrylak DP, Benson MC, Silva JM, et al.
Suppression of acquired docetaxel resistancein prostate cancer through depletion of notch- and hedgehog-dependent tumor initiating cells. Cancer Cell. 2012; 22:373-388.

38. Espinoza I, Pochampally R, Xing F, Watabe K, Miele L. Notch signaling: targeting cancer stem cells and epithelialto-mesenchymal transition. Onco Targets Ther. 2013; 6:1249-1259.

39. Zhao B, Tumaneng K, Guan KL. The Hippo pathway in organ size control, tissue regeneration and stem cell selfrenewal. Nat Cell Biol. 2011; 13:877-883.

40. Lei QY, Zhang H, Zhao B, Zha ZY, Bai F, Pei XH, Zhao S, Xiong Y, Guan KL. TAZ promotes cell proliferation and epithelial-mesenchymal transition and is inhibited by the hippo pathway. Mol Cell Biol. 2008; 28:2426-2436.

41. Hiemer SE, Varelas X. Stem cell regulation by the Hippo pathway. Biochim Biophys Acta. 2013; 1830:2323-2334.

42. Marino N, Nakayama J, Collins JW, Steeg PS. Insights into the biology and prevention of tumor metastasis provided by the Nm23 metastasis suppressor gene. Cancer Metastasis Rev. 2012; 31:593-603.

43. Nash KT, Welch DR. The KISS1 metastasis suppressor: mechanistic insights and clinical utility. Front Biosci. 2006; 11:647-659.

44. Hartsough M, Steeg P. Nm23/nucleoside diphosphate kinase in human cancers. J Bioenerg Biomembr. 2000; 32:301-308.

45. Wang H, Jones J, Turner T, He QP, Hardy S, Grizzle WE, Welch DR, Yates C. Clinical and biological significance of KISS1 expression in prostate cancer. Am J Pathol. 2012; 180:1170-1178.

46. Rumpold H, Heinrich E, Untergasser G, Hermann M, Pfister G, Plas E, Berger P. Neuroendocrine differentiation of human prostatic primary epithelial cells in vitro. Prostate. 2002; 53:101-108.

47. Meulemans D, Bronner-Fraser M. Gene-regulatory interactions in neural crest evolution and development. Dev Cell. 2004; 7:291-299.

48. Sakai D, Suzuki T, Osumi N, Wakamatsu Y. Cooperative action of Sox9, Snail2 and PKA signaling in early neural crest development. Development. 2006; 133:1323-1233.

49. Young RH, Srigley JR, Amin MB, Ulbright TM, Cubilla AL, (eds). Tumors of the Prostate Gland, Seminal Vesicles, Male Urethra, and Penis. AFIP Atlas of Tumor Pathology, Series, III. (Washington DC: Armed Forces Institute of Pathology), 2000; p. 129.

50. Sobin LH, Gospodarowicz MK, Wittekind C, (eds). TNM Classificazione dei tumori maligni. 7th ed, Milan: Raffaello Cortina Editore, 2009; pp. 241-245.

51. Landis JR, Koch GG. The measurement of observer agreement for categorical data. Biometrics. 1977; 33:159-174. 